\title{
EFFECT OF INTRALESIONAL CURETTAGE AND CEMENTATION IN THE TREATMENT OF GIANT CELL TUMOUR AROUND KNEE AND ANKLE JOINTS
}

\author{
Surendra Singh Yadavi, Rao Anand ${ }^{2}$, Saiyam Shelendra ${ }^{3}$ \\ ${ }^{1}$ Assistant Professor, Department of Orthopaedics, G. R. Medical College, Gwalior. \\ ${ }^{2}$ Resident Surgeon, Department of Orthopaedics, G. R. Medical College, Gwalior. \\ ${ }^{3}$ Assistant Professor, Department of Orthopaedics, G. R. Medical College, Gwalior.
}

\begin{abstract}
OBJECTIVE

Giant cell tumours (GCT) of bone are benign tumours with local aggressiveness that most of the time occur around the metaphyseal area of long bones, often in contact with the articular cartilage. They account for about 5\% of all primary bone tumours, their treatment remains controversial because of their high recurrence rate. In this study, a series of 28 cases treated using curettage followed by bone cementation. We studied the functional benefit of this technique and its benefit in controlling the risk of recurrence.
\end{abstract}

\section{MATERIAL AND METHODS}

Between 2012 and 2015, 28 patients with GCT were treated using curettage and bone cementation. Sixteen of these tumours were present at the distal femur and eight at the proximal tibia, four at distal tibia. All patients were screened preoperatively by radiological evaluation with standard X-rays which showed the characteristic soap bubble appearance and all the cases were confirmed histologically by biopsy before they were treated with curettage and bone cementation. The mean follow-up was 3 years. All patients continue to be monitored, with no patient lost to follow-up.

\section{RESULTS}

In all our cases, two recurrences were observed in 3 years in patients treated with curettage and cementation procedure which required repeated curettage and cementation. We conclude that intralesional curettage and bone cement packing is one of the best treatment options for GCT lesions with less recurrence rate.

\section{KEYWORDS}

Giant Cell Tumour, Cement, Curettage, PMMA.

HOW TO CITE THIS ARTICLE: Yadav SS, Anand R, Shelendra S. Effect of intralesional curettage and cementation in the treatment of giant cell tumour around knee and ankle joints. J. Evolution Med. Dent. Sci.2016;5(72):5311-5314, D0I: $10.14260 /$ jemds/2016/1203

\section{INTRODUCTION}

Giant cell tumours (GCT) of bone are benign tumours with local aggressiveness that most frequently occur around the metaphyseal area of long bones with frequent invasion of subchondral bone, often in contact with joint cartilage. These are relatively frequent tumours accounting for $4-5 \%$ of bone tumours and $21 \%$ of benign tumours of the bone according to Babinet ${ }^{1}$ and Campanacci et al. $^{2}$ Joint extension is exceptional. Treatment of the peri-articular tumours remains controversial because of the high recurrence rate. Resection treats the tumour and prevents the risk of recurrence at the cost of a less desirable functional result. ${ }^{3}$ Electrocautery, burring, phenol irrigation, cementation, cryosurgery with liquid nitrogen, selective embolisation, and radiation are considered most effective. $4,5,6$

Bone cement has the advantages of preservation of dynamic stability, thus allowing rapid loading, early mobilisation and detection of recurrence with radiological observation of lysis at the cement-bone interface, the toxic properties of the methyl methacrylate monomer and the

Financial or Other, Competing Interest: None.

Submission 21-01-2016, Peer Review 25-08-2016,

Acceptance 31-08-2016, Published 08-09-2016.

Corresponding Author:

Dr. Surendra Singh Yadav,

A-1/17, Sector-4,

Vinay Nagar, Gwalior,

Madhya Pradesh.

E-mail: drsurend15@gmail.com

DOI: $10.14260 /$ jemds/2016/1203 necrotic effect of the heat given off during polymerisation on the tumour cells. It can also be used at the onset of pathological fracture. We have studied the results of this method on the recurrence rate and functional outcome. The series presented includes 16 cases at the distal femur, 8 cases at the proximal tibia and 4 at distal tibia.

\section{MATERIAL AND METHOD}

Between 2012 and 2015, 28 patients (18 females and 10 males) with a mean age of 39 years (range 18-60), with GCT of the long bones were treated using the curettage and cementation technique. Diagnosis was based on histological examination of biopsy material taken before any therapeutic act in all cases. It was a prospective study, and cases selected for the study were Campanacci grade II and grade III tumours.

This study includes sixteen cases of the distal femur, eight cases of the proximal tibia and four of distal tibia affected with Giant cell tumours, the intervention consisted of thorough curettage of the cavity and the walls, then filling the intraosseous cavity with Bone cement (PMMA). In two cases, Bone cementation along with Plate fixation was done to stabilise the pathological fracture occurred. All the patients were followed up for three complete years once in a month and serial $\mathrm{x}$-rays were taken to check for the recurrence and movement of the nearest joint.

\section{RESULT}

During the clinical and radiological follow-up of the patients who had undergone treatment, two recurrences were noted 
on follow-up x-rays in 3 years following surgery, one at the distal femur and another at proximal tibia which were managed by repeated curettage and cementation, no other complications are noted like infection or difficulty in removing cement. The recurrence rate amounts to $14 \%$ in our study.
After 3 years of continuous follow-up, the function of the operated limb was studied using the Knee Society Score and AOFAS (American Orthopaedic Foot and Ankle Society) score. In our study, the mean score was 85 (Excellent) which is ranging from 65-95.

\begin{tabular}{|c|c|c|c|c|c|}
\hline Sl. No. & Age & Sex & $\begin{array}{c}\text { Location of } \\
\text { tumour }\end{array}$ & $\begin{array}{c}\text { Functional } \\
\text { Score }\end{array}$ & Recurrence \\
\hline 1 & 24 years & Female & Distal Femur & 95 (Excellent) & No \\
\hline 2 & 18 years & Female & Distal Femur & 85 (Excellent) & No \\
\hline 3 & 19 years & Male & Proximal Tibia & 90 (Excellent) & No \\
\hline 4 & 45 years & Male & Distal Femur & 90 (Excellent) & No \\
\hline 5 & 48 years & Female & Proximal Tibia & 85 (Excellent) & No \\
\hline 6 & 44 years & Male & Distal Femur & 90 (Excellent) & No \\
\hline 7 & 54 years & Male & Distal Femur & 85 (Excellent) & No \\
\hline 8 & 56 years & Female & Distal Femur & 90 (Excellent) & No \\
\hline 9 & 42 years & Female & Distal Femur & 80 (Excellent) & No \\
\hline 10 & 38 years & Male & Distal tibia & 90 (Excellent) & No \\
\hline 11 & 26 years & Female & Proximal Tibia & 90 (Excellent) & No \\
\hline 12 & 22 years & Male & Proximal Tibia & 85 (Excellent) & No \\
\hline 13 & 48 years & Female & Proximal Tibia & 75 (Good) & No \\
\hline 14 & 18 years & Male & Proximal tibia & 65 (Fair) & Yes \\
\hline 15 & 22 years & Male & Proximal Tibia & 80 (Excellent) & No \\
\hline 16 & 56 years & Female & Distal Femur & 75 (Good) & No \\
\hline 17 & 44 years & Female & Distal Femur & 85 (Excellent) & No \\
\hline 18 & 32 years & Male & Proximal Tibia & 90 (Excellent) & No \\
\hline 19 & 54 years & Female & Distal Femur & 85 (Excellent) & No \\
\hline 20 & 46 years & Female & Distal Tibia & 90 (Excellent) & No \\
\hline 21 & 19 years & Female & Distal Femur & 80 (Excellent) & Yes \\
\hline 22 & 46 years & Male & Distal tibia & 85 (Excellent) & No \\
\hline 23 & 52 years & Female & Distal Femur & 80 (Excellent) & No \\
\hline 24 & 60 years & Female & Distal Femur & 90 (Excellent) & No \\
\hline 25 & 40 years & Female & Distal Femur & 85 (Excellent) & No \\
\hline 26 & 38 years & Female & Distal tibia & 90 (Excellent) & No \\
\hline 27 & 44 years & Female & Distal Femur & 90 (Excellent) & No \\
\hline 28 & 42 Years & Female & Distal Femur & 90 (Excellent) & No \\
\hline
\end{tabular}
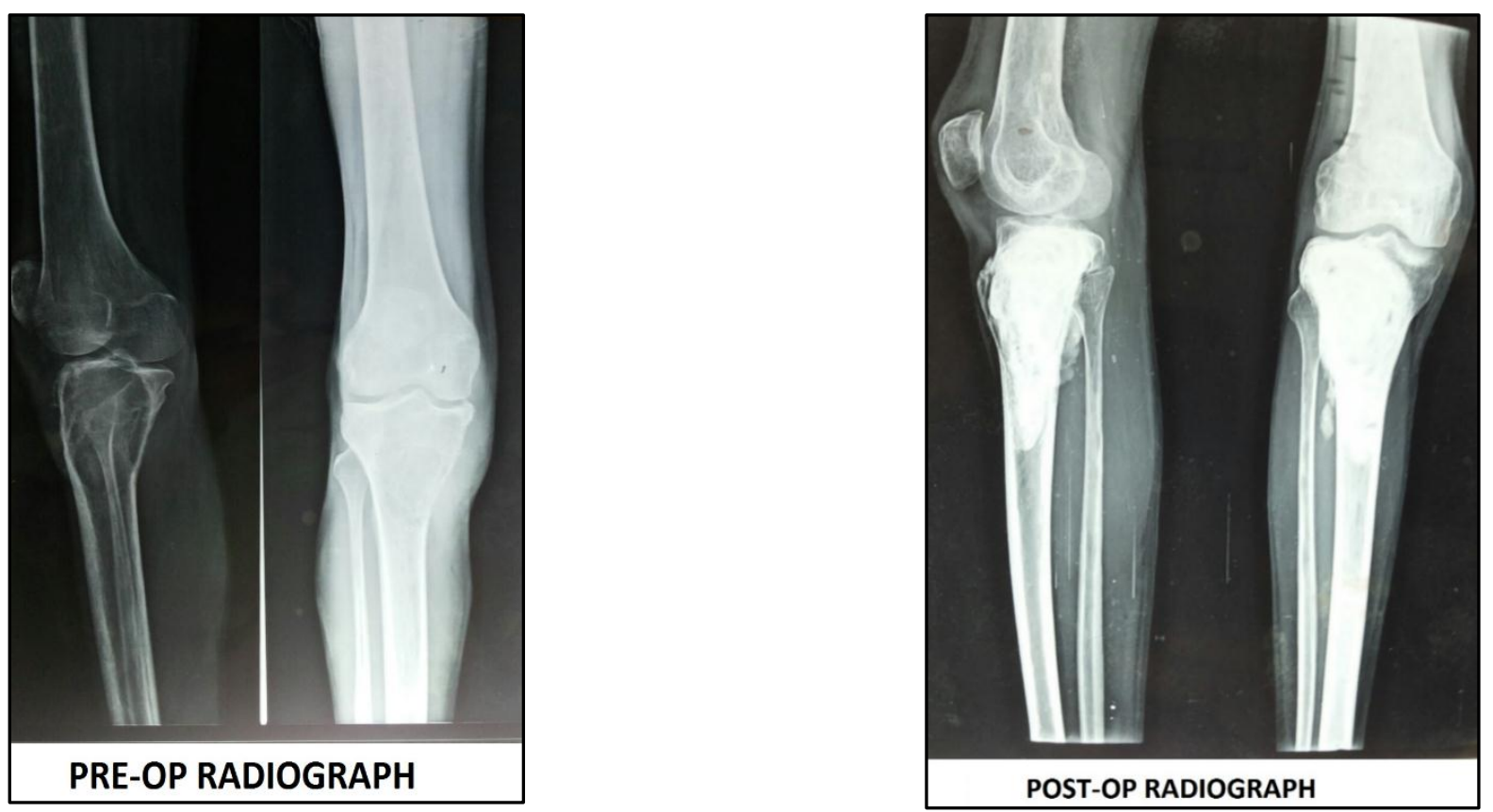

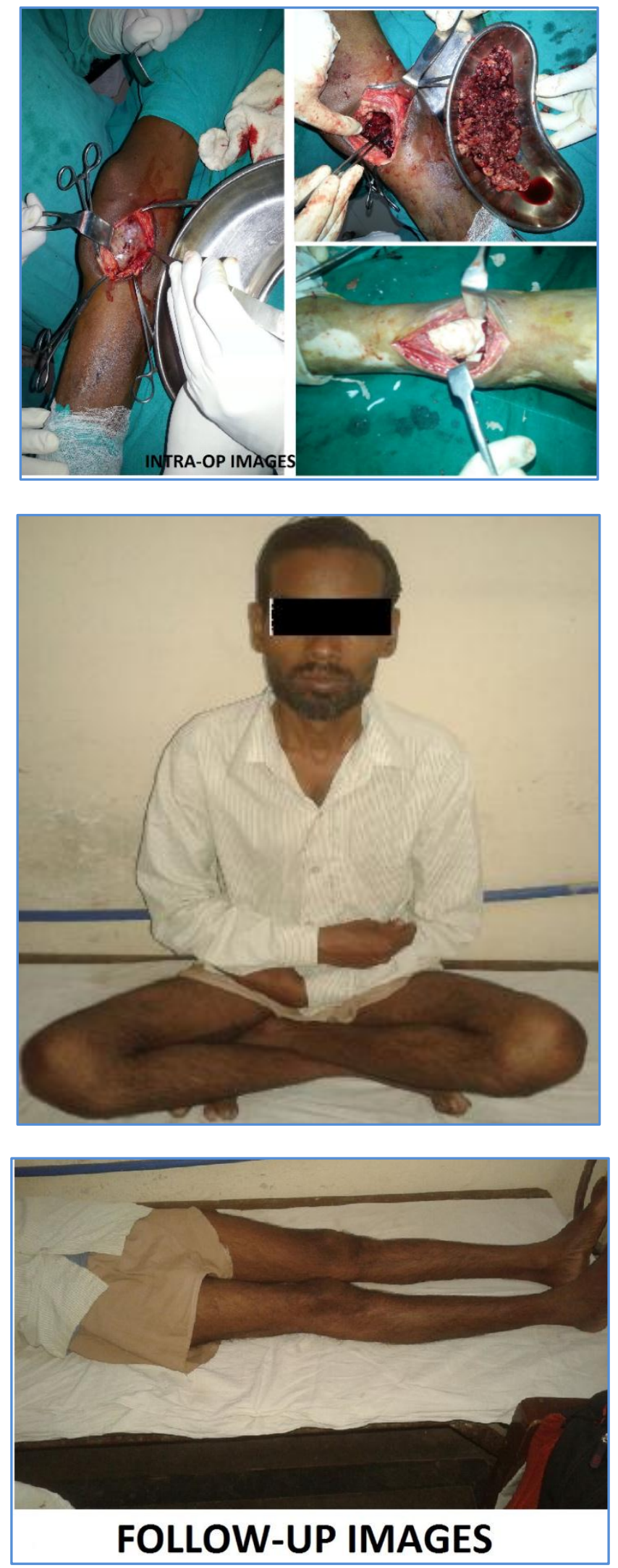

\section{DISCUSSION}

Giant cell tumours are the aggressive benign tumours ( $2 \%$ malignant) which generally occur in adults of age group 20-40 years. It is rarely seen in children and adults above the age of 65 years. Various techniques are being used since the past to reduce the rate of recurrence of these tumours, but no method is satisfactory.
Depending on the grade of the tumour, intralesional/ marginal excision, wide resection with reconstruction, radiation, en block resection and reconstruction are advised but they are still controversial.

Bone curettage and intralesional filling with the bone cement is one of the treatment modality advised in the management of these tumours. Bone cement is chemically Polymethyl methacrylate which has some advantages like, it acts as a cytotoxic on tumour cells, the heat produced during the polymerisation may help extend the boundary of tumour kill. Bone tumour also gives structural support and allows rapid weight-bearing, makes early detection of recurrence easier on radiograph. It also has some of the disadvantages like as it is not a biological material; it is relatively weak when subjected to shear and torsional forces. Hence, its use in lesions involving the head and neck of the femur may result in an increased chance of fractures through cement. There is also fear about long-term degeneration of articular cartilage in subchondral lesions in weight-bearing areas, ${ }^{7}$ infection and difficulty in removing on revision procedures.

We studied 28 cases of giant cell tumours around the knee and ankle joint, all are treated with extensive curettage and cementation. Bone cement is being used in reconstructive surgery since more than 30 years (Blum 1944) and has shown good compressive strength making it suitable for defects at the end of long bones, as in giant cell tumours. ${ }^{8}$ We achieved excellent result in $89 \%$ of cases with a recurrence rate of $14 \%$.

In 1994, R JO'Donnell et $\mathrm{al}^{9}$ studied 60 patients with giant cell tumour of long bones treated with curettage and polymethyl methacrylate cement. An average of four years after the operation, the overall rate of initial local recurrence was $25 \%$ (fifteen of sixty patients). Patients who had a tumour of the distal aspect of the radius had a higher rate of recurrence (five of ten) than those who had had a tumour of the proximal aspect of the tibia (28 percent) or of the distal part of the femur $(13 \%)$. Higher rates of recurrence were also noted for patients who had had a pathological fracture, those who had had a stage III tumour according to the classification of Campanacci et al and those who had not had adjuvant treatment with either a high-speed burr or phenol. Patients who had an initial recurrence after packing with cement had a low rate of secondary recurrence when the initial recurrence had been treated with a wide resection or a second intralesional procedure after an average of three years.

Bini et $\mathrm{al}^{10}$ in 1995 conducted a retrospective study of 38 patients treated with curettage and acrylic cement reconstruction. He followed them for a mean period of 5.2 years and noted that there were no infections or mechanical failures of the construct. Functional results were good to excellent in $84 \%$ of patients. Ninety-five percent of patients were reported good or excellent stability, no deformity, and emotional acceptance of the procedure. The recurrence rate with this protocol (8\%) approached to that associated with wide resection or amputation (0\%-5\%) and was lower than that seen with simple curettage and bone grafting (27\%-55\%).

Fraquet $\mathrm{N}$ et al in 2009 studied 30 cases of Giant cell tumours and observed a recurrence rate of $30 \%$. Subsequent curettage and cementation after recurrence shows no further recurrence. 
Another study by Gao et al ${ }^{11}$ in 2014 showed $24.6 \%$ recurrence rate out of 65 patients they studied. Thirteen patients $(81.3 \%)$ had a local recurrence within 2 years after surgery. Only 3 patients (18.7\%) had a recurrence after 2 years,

Most recurrences of giant cell tumours are to be expected in 3 years following surgey.5,6,12 Hence, we followed up all our patients till 3 years.

\section{CONCLUSION}

GCT can be treated easily and effectively with curettage and cementation with excellent functional results at the medium term. All the mechanical and cytotoxic properties of the cement make it a very good adjuvant agent in the treatment of GCT. In our study, only $14 \%$ recurrence rate with bone cementation shows that curettage with PMMA cement is a safe and effective procedure.

\section{REFERENCES}

1. Babinet A. Tumeur à cellule géantes: cahier d'enseignement de la sofcot. Elsevier SAS: Paris, France 2005:201-19.

2. Campanacci M, Baldini N, Boriani S, et al. Giant cell tumor of bone. J Bone Joint Surg Am 1987;69(1):106-14.

3. Fraquet $\mathrm{N}$, Faizon $\mathrm{G}$, Rosset $\mathrm{P}$, et al. Long bones giant cells tumors: treatment by curettage and cavity filling cementation. Orthop Traumatol Surg Res 2009;95(6): 402-6.
4. Sung HW, Kuo DP, Shu WP, et al. Giant cell tumor of bone: analysis of two hundred and eight cases in Chinese patients. J Bone Joint Surg Am 1982;64(5):755-61.

5. Malawer MM, Bickels J, Meller L, et al. Cryosurgery in the treatment of giant cell tumor. A long-term followup study. Clin Orthop Relat Res 1999;(359):176-88.

6. Turcotte RE, Isler M, Doyon J. Tumeur à cellules géantes. In: Encyclopédiemedico chirurgicale: appareillocomoteur. Paris, France: Elsevier SAS 2001:14-772.

7. Manley PA, McKeown DB, Schatzker J, et al. Replacement of epiphyseal bone with methyl methacrylate: its effect on articular cartilage. Arch Orthop Trauma Surg 1982;100 (1):3-10.

8. Persson BM, Wouters HW. Curettage and acrylic cementation in surgery of giant cell tumors of bone. Clin Orthop Relat Res 1976;(120):125-33.

9. O'Donnell RJ, Springfield DS, Motwani HK, et al. Recurrence of giant-cell tumors of the long bones after curettage and packing with cement. J Bone Joint Surg Am 1994;76(12):1827-33.

10. Bini SA, Gill K, Johnston JO. Giant cell tumor of bone. Curettage and cement reconstruction. Clinical Orthop Relat Res 1995;(321):245-50.

11. Gao ZH, Yin JQ, Xie XB, et al. Local control of giant cell tumors of the long bone after aggressive curettage with and without bone cement. BMC Musculoskeletal Disorders 2014;15:330.

12. Lorentzon R. Genuine giant cell tumor of bone. Umea university medical dissertations no. 1978:33. 